\title{
Conversion gastrectomy for stage IV unresectable gastric cancer: a GIRCG retrospective cohort study
}

\author{
Leonardo Solaini ${ }^{1}\left[\right.$ - Silvia Ministrini ${ }^{2} \cdot$ Maria Bencivenga $^{3}$ - Alessia D'lgnazio ${ }^{4}$. Elisabetta Marino ${ }^{5}$. \\ Chiara Cipollari ${ }^{3}$ - Beatrice Molteni ${ }^{2} \cdot$ Gianni Mura $^{6}$ - Daniele Marrelli ${ }^{4} \cdot$ Luigina Graziosi $^{5} \cdot$ Franco Roviello $^{4}$. \\ Giovanni De Manzoni ${ }^{3} \cdot$ Guido A. M. Tiberio $^{2} \cdot$ Paolo Morgagni $^{1}$
}

Received: 21 December 2018 / Accepted: 25 April 2019 / Published online: 7 May 2019

(c) The International Gastric Cancer Association and The Japanese Gastric Cancer Association 2019

\begin{abstract}
Background The aim of this study is to report the experience with conversion surgery from six Gruppo Italiano Ricerca Cancro Gastrico (GIRCG) centers, focusing our analysis on factors affecting survival and the risk of recurrence.

Methods A retrospective, multicenter cohort study was performed in patients who had undergone conversion gastrectomy between 2005 and 2017. Data were extracted from a GIRCG database including all metastatic gastric cancer patients submitted to surgery. Only stage IV unresectable tumors/metastases which became resectable after chemotherapy were included in this analysis.

Results Forty-five resected M1 patients were included in the analysis. Reasons for being deemed unresectable at diagnosis were peritoneal involvement $(\mathrm{PCI}>6)(n=38,84.4 \%)$, distant metastatic nodes $(n=3,6.6 \%)$ and extensive liver involvement $(n=4,8.8 \%)$. Median follow-up was 25 months (IQR 9-50). Median overall survival from surgery was 15 months and 1-, 3 - and 5-year survivals were 57.2, 36.1 and 24\%, respectively. Median progression-free survival was 12 months with 1- and 3 -year survival of 46.4 and $33.9 \%$, respectively. At cox regression analysis the only independent prognostic factor for OS was the presence of more than one type of metastasis (HR 4.41, 95\% CI 1.72-11.3, $p=0.002)$. A positive microscopic resection margin was the only risk factor for recurrence (HR 5.72, 95\% CI 1.04-31.4, $p=0.045$ ).

Conclusions Unresectable stage IV GC patients could benefit from radical surgery after chemotherapy and achieve long survivals. The main prognostic factor for these patients was the presence of more than one type of extra-gastric metastatic involvement.
\end{abstract}

Keywords Stage IV gastric cancer $\cdot$ Conversion surgery $\cdot$ Palliative chemotherapy $\cdot$ Metastases $\cdot$ Gastrectomy $\cdot$ Survival

Paolo Morgagni

morgagni2002@libero.it

1 General and Oncologic Surgery, Department of Surgery, Morgagni-Pierantoni Hospital, Via Forlanini 34, Forlì, Italy

2 Department of Experimental and Clinical Sciences, University of Brescia, Brescia, Italy

3 General and Upper GI Surgery Division, University of Verona, Verona, Italy

4 Department of Surgery, Policlinico le Scotte- University of Siena, Siena, Italy

5 Department of Surgery, Santa Maria della Misericordia Hospital University of Perugia, Perugia, Italy

6 Department of Surgery, Azienda USI Toscana SudEst- Arezzo, Arezzo, Italy

\section{Introduction}

Stage IV gastric cancer carries a poor prognosis. As per current guidelines $[1,2]$ the only therapeutic option for these patients could be palliative chemotherapy which may offer survivals up to 24 months [3]. However, there is growing literature reporting long survivals in those cases (stage IV gastric cancer) who responded to palliative chemotherapy and were subsequently submitted to gastrectomy [4-11]. In particular, this multimodal treatment, which was defined as conversion surgery, could be associated with significant improved survivals of more than 40 months when R0 resection could have been achieved $[5,11]$.

Still, literature about conversion surgery is scarce and studies are usually characterized by limited sample sizes and 
different definitions [7, 12]. In addition, to date, all but one study was performed on a cohort from a western center [7].

With this paper, we aim to report the experience of six GIRCG centers with conversion surgery, focusing our analysis on factors affecting survival and the risk of recurrence.

\section{Materials and methods}

\section{Study design}

A retrospective, multicenter cohort study was performed in patients who had undergone conversion gastrectomy April 1, 2005 and January 1, 2017 in 6 centers belonging to Gruppo Italiano Ricerca Cancro Gastrico (GIRCG) centers. Data were extracted from a GIRCG database including all metastatic gastric cancer patients submitted to surgery. Only stage IV GC which became resectable, (showing partial or complete response) after chemotherapy were included in this analysis.

\section{Definitions}

Patients' diagnosis, treatment and perioperative care were performed as recommended by GIRCG guidelines in all participating centers [2]. Conversion surgery was defined as a surgical treatment aiming at $\mathrm{R} 0$ resection for tumors that were deemed unresectable before chemotherapy. As per study protocol, the definition of an unresectable tumor/ metastasis before chemotherapy was based on technical and oncological reasons and included: peritoneal cancer index (PCI) (as defined by Sugarbaker et al. [13]) $>6$, bilobar hepatic metastases, nodal involvement outside D1-3 stations, technically unresectable metastases.

Staging laparoscopy was performed in all patients before chemotherapy. The re-assessment for resectability was based on the imaging performed during treatment at 3-6 months. Surgery was proposed only to those patients in whom gastrectomy and associated resections could have been potentially radical. In particular, the peritoneal involvement was considered for treatment only in case of $\mathrm{PCI}<6$ at exploration after palliative chemotherapy.

All specimens were histopathologically classified according to Lauren's microscopic criteria [14]. Tumor stage was presented as indicated by the Union for International Cancer Control (UICC)/American Joint Committee on Cancer (AJCC) [15]. All cases were also grouped as proposed by Yoshida et al. [16].

\section{Variables}

Baseline characteristics collected included sex, age, American Society of Anaesthesiologists (ASA) score, type $\mathrm{f}$ preoperative chemo- and/or radiotherapy, preoperative staging (pTNM). Operative variables collected included type of procedure and lymphadenectomy, additional resections, intraoperative multimodal treatments and number of lymphnode harvested. Tumor-related variables included pathology stage (pTNM), resection margin status, tumor regression grade, Lauren's histotype and grading. Complications were all collected up to the day of discharge and graded according to Clavien et al. [17]. Progression-free survival (PFS) and overall survival(OS) were the primary outcome measures.

\section{Statistical analysis}

Continuous data were presented as median and interquartile range (IQR). The Kaplan-Meier curve was used to calculate survival rates. OS was calculated as the time between both diagnosis and surgery and death/last follow-up. PFS was defined as the time between surgery and the first evidence of disease recurrence/progression and was calculated for all patients excluding $\mathrm{R} 2$ resections. Cox regression was performed to find independent factors affecting survival after surgery. Hazard ratios (HR) and $95 \%$ confidence intervals (95\% CI) were calculated when required. Only variables with $p<0.050$ at univariate analysis were entered in multivariable analyses in a stepwise manner. Follow-up was calculated as recommended elsewhere [18]. Analyses were performed with MedCalc Statistical Software (MedCalc Software bvba, Ostend, Belgium).

\section{Results}

In total, 287 stage IV GC patients were screened, of whom 242 were excluded for reasons (193 had no preoperative chemotherapy, 38 had preoperative chemotherapy for technically resectable disease, 11 had no details about preoperative period), leaving 45 patients for analysis. Patients' characteristics at diagnosis are presented in Table 1. Reasons for being deemed unresectable at diagnosis were peritoneal involvement $(n=38,84.4 \%)$, distant metastatic nodes $(n=3$, $6.6 \%)$ and extensive liver involvement $(n=4,8.8 \%)$.

Operative variables are shown in Table 2. In 33 (73.3\%) cases peritoneal resections were required while in 3 these were not performed due to the extent of the disease. Two patients with peritoneal involvement had complete response after palliative chemotherapy and peritonectomy procedures were not performed as no residual disease was found. Postoperative complications occurred in 18 (40\%) patients; and they had a Clavien-Dindo grade above 2 in 14 cases (31.1\%). Tumor-related variables are presented in Table 3.

Median follow-up was 25 months (IQR 9-50). Median overall survival was 15 months and 1-, 3- and 5-year survivals were 57.2, 36.1 and $24 \%$, respectively (Fig. 1). Median 
Table 1 Patients' characteristics at diagnosis

\begin{tabular}{|c|c|}
\hline Age-median (IQR) & $54(48-61)$ \\
\hline Female, $n(\%)$ & $18(40)$ \\
\hline $\mathrm{ASA}>2, n(\%)$ & $2(4.1)$ \\
\hline \multicolumn{2}{|l|}{ Tumor site, $n(\%)$} \\
\hline Upper third & $6(13.3)$ \\
\hline Middle third & $12(26.7)$ \\
\hline Lower third & $18(40)$ \\
\hline Linitis & $9(20)$ \\
\hline \multicolumn{2}{|l|}{$\mathrm{cT}, n(\%)$} \\
\hline $\mathrm{cT} 3$ & $9(20)$ \\
\hline cT4 & $33(73.3)$ \\
\hline Not available & $3(6.7)$ \\
\hline \multicolumn{2}{|l|}{$\mathrm{cN}, n(\%)$} \\
\hline N0 & $10(22.2)$ \\
\hline $\mathrm{N}+$ & $35(77.8)$ \\
\hline \multicolumn{2}{|l|}{$\mathrm{cM}, n(\%)$} \\
\hline M1 & $45(100)$ \\
\hline Positive peritoneal cytology $n(\%)$ & $10(22.2)$ \\
\hline \multicolumn{2}{|l|}{ Yoshida types } \\
\hline 1 & $0(0)$ \\
\hline 2 & $7(15.5)$ \\
\hline 3 & $29(64.4)$ \\
\hline 4 & $9(20)$ \\
\hline \multicolumn{2}{|l|}{ Types of palliative chemotherapy } \\
\hline Cisplatin plus fluoropyrimidine & $20(44.4)$ \\
\hline Epirubicin and Cisplatin plus fluoropyrimidine & $9(20)$ \\
\hline Docetaxel and Oxaliplatin plus fluoropyrimidine & $9(20)$ \\
\hline Other types & $7(15.5)$ \\
\hline
\end{tabular}

Table 2 Operative variables

\begin{tabular}{ll}
\hline Type of procedure, $n(\%)$ & $33(73.3)$ \\
Total gastrectomy & $12(26.7)$ \\
Subtotal gastrectomy & \\
Type of lymphadectomy, $n(\%)$ & $4(8.9)$ \\
D1 & $19(42.2)$ \\
D2 & $22(48.9)$ \\
D3 & \\
Additional procedure, $n(\%)$ & $23(51.1)$ \\
None & $7(15.5)$ \\
$>1$ additional resection & $6(13.3)$ \\
Colectomy & $5(11.1)$ \\
Splenectomy & $2(4.4)$ \\
Distal pancreatectomy & $1(2.2)$ \\
Small bowel resection & $1(2.2)$ \\
Distal splenopancreatectomy & $23(51.1)$ \\
HIPEC, $n(\%)$ & \\
\hline
\end{tabular}

HIPEC hyperthermic intraperitoneal chemotherapy
Table 3 Pathology variables

Residual disease, $n(\%)$

R0

$30(66.6)$

R1 7 (15.5)

R2

$8(17.7)$

Gastric margin status, $n(\%)$

R0

$40(88.9)$

R1

$5(11.1)$

pT

$\mathrm{T} 2$

2 (4.4)

15 (33.3)

23 (51.1)

5 (11.1)

3 (6.6)

5 (11.1)

7 (15.5)

$10(22.2)$

17 (37.8)

3 (6.6)

$\mathrm{Nx}$

pM

M1

$45(100)$

Lymphnodes harvested n (\%)

$3(6.6)$

$<16$

$2(4.4)$

15-29

13 (28.9)

13 (28.9)

45-59

13 (28.9)

$60-74$

$1(2.2)$

TRG T site $(n=28)$

7 (14.3)

8 (16.3)

13 (26.5)

Not specified

$21(42.8)$

Lauren's hystotype, $n(\%)$

Intestinal

$11(24.4)$

Diffuse

$29(64.4)$

Mixed

4 (8.8)

Not specified

$1(2.2)$

Tumor grade

G2

$4(8.8)$

G3 34 (75.5)

Not specified

$7(15.5)$

$T R G$ tumor regression grade

OS calculated from diagnosis of GC was 20.6 months with 1-, 3- and 5-year survival of 78.2, 38.6 and 26.5\%. Median PFS was 12 months with 1- and 3-year survival of 46.4 and 33.9\%, respectively (Fig. 2).

At cox regression analysis the only independent prognostic factor for OS was the presence of more than one type of 
Fig. 1 Kaplan-Meier curve of overall survival for the whole cohort

Fig. 2 Kaplan-Meier curve of progression free survival
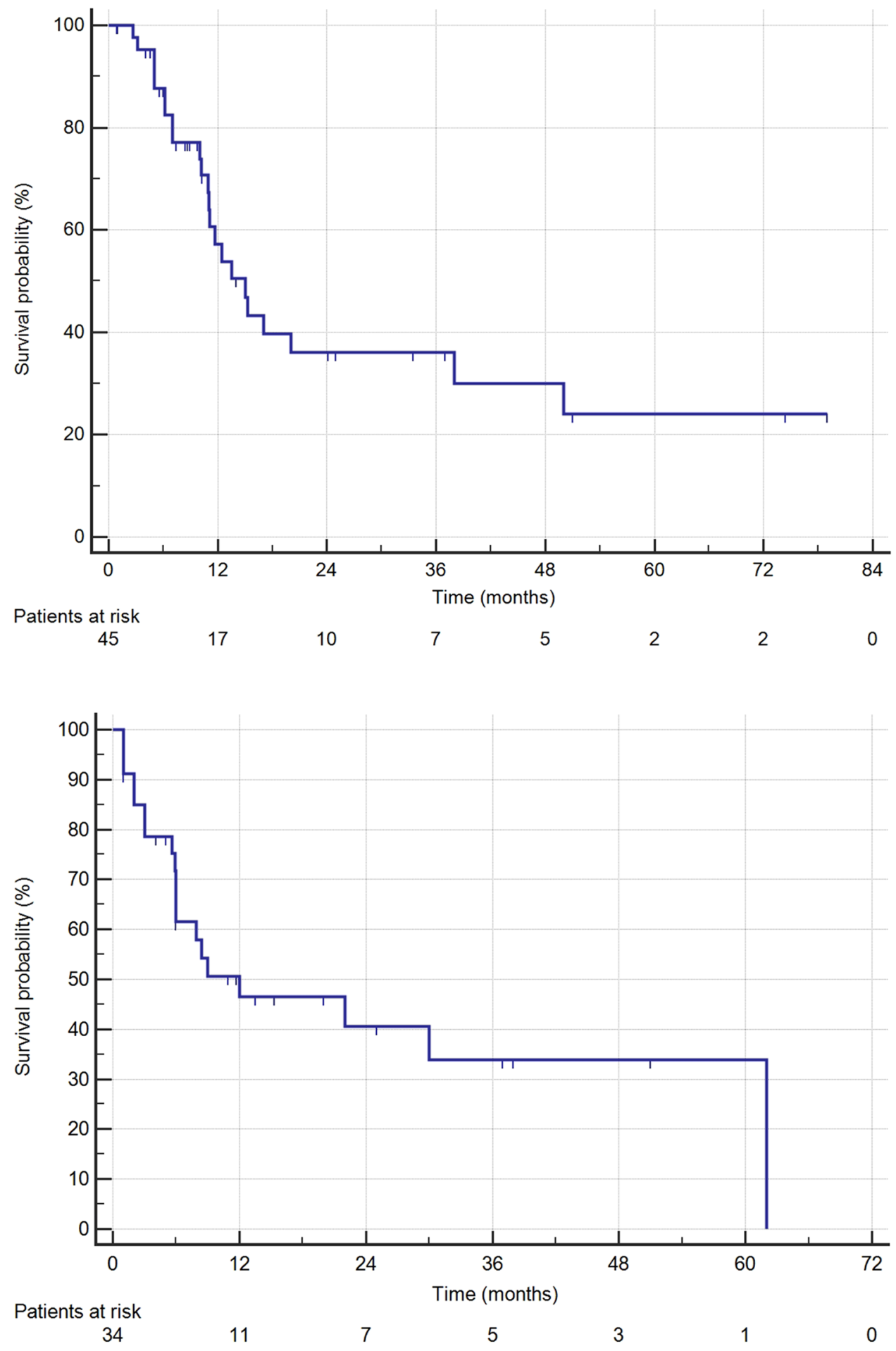

metastasis (HR 4.41, 95\% CI 1.72-11.3, $p=0.002$ ) (Table 4) (Fig. 3). A positive microscopic resection margin was the only risk factor for recurrence (HR 5.72, 95\% CI 1.04-31.4, $p=0.045)$ (Table 5).

\section{Discussion}

Stage IV unresectable gastric cancer patients could benefit from surgery, which may offer prolonged survival.

More than 20 years ago, first, Nakajima et al. [8] described similar findings. Authors showed that unresectable 
Table 4 Cox regression analysis of overall survival

\begin{tabular}{|c|c|c|c|c|c|}
\hline \multirow[t]{3}{*}{ Variable } & \multirow[t]{3}{*}{$n$} & \multicolumn{4}{|l|}{ OS } \\
\hline & & \multicolumn{2}{|l|}{ Univariate } & \multicolumn{2}{|l|}{ Multivariate } \\
\hline & & HR $(95 \%$ CI) & $P$ & HR $(95 \%$ CI $)$ & $p$ \\
\hline Age* & 45 & $1.01(0.96-1.05)$ & 0.467 & & \\
\hline \multicolumn{6}{|l|}{ Sex } \\
\hline Male & 27 & 1.00 & 1.000 & & \\
\hline Female & 18 & $0.75(0.31-1.84)$ & 0.536 & & \\
\hline ASA & 43 & 1.00 & 1.000 & & \\
\hline$\leq 2$ & 2 & $2.76(0.63-12.1)$ & 0.180 & & \\
\hline \multicolumn{6}{|l|}{$>2$} \\
\hline \multicolumn{6}{|l|}{ cT } \\
\hline cT3 & 9 & 1.00 & 0.000 & & \\
\hline cT4 & 33 & $1.91(0.56-6.49)$ & 0.305 & & \\
\hline \multicolumn{6}{|l|}{$\mathrm{cN}$} \\
\hline $\mathrm{cNO}$ & 10 & 1.00 & 1.000 & & \\
\hline $\mathrm{cN}+$ & 35 & $1.29(0.67-2.51)$ & 0.444 & & \\
\hline \multicolumn{6}{|l|}{ Type of lymphadenectomy } \\
\hline D1 & 4 & 1.00 & 1.000 & & \\
\hline D2 & 19 & $0.46(0.12-1.72)$ & 0.253 & & \\
\hline D3 & 22 & $0.27(0.07-1.07)$ & 0.065 & & \\
\hline \multicolumn{6}{|l|}{ Additional resection } \\
\hline No & 23 & 1.00 & 1.000 & & \\
\hline Yes & 22 & $1.35(0.58-3.13)$ & 0.485 & & \\
\hline \multicolumn{6}{|l|}{ HIPEC } \\
\hline No & 22 & 1.00 & 1.000 & & \\
\hline Yes & 23 & $0.85(0.37-1.91)$ & 0.689 & & \\
\hline \multicolumn{6}{|l|}{ Postoperative complications } \\
\hline No & 27 & 1.00 & 1.000 & & \\
\hline Yes & 18 & $0.80(0.33-1.94)$ & 0.622 & & \\
\hline Lymphnode harvested* & 45 & $0.97(0.93-1.01)$ & 0.108 & & \\
\hline \multicolumn{6}{|l|}{ Grading } \\
\hline G2 & 4 & 1.00 & 1.000 & & \\
\hline G3 & 34 & $1.04(0.30-3.56)$ & 0.949 & & \\
\hline \multicolumn{6}{|l|}{ Lauren's hystotype } \\
\hline Intestinal & 11 & 1.00 & 1.000 & & \\
\hline Diffuse & 29 & $0.87(0.37-2.32)$ & 0.877 & & \\
\hline Mixed & 4 & $4.16(1.01-17.2)$ & 0.049 & & \\
\hline \multicolumn{6}{|l|}{ pT } \\
\hline $\mathrm{pT}<4$ & 17 & 1.00 & 1.000 & & \\
\hline pT4a-b) & 28 & $1.5(0.62-3.62)$ & 0.365 & & \\
\hline \multicolumn{6}{|l|}{$\mathrm{pN}$} \\
\hline No & 3 & 1.00 & 1.000 & & \\
\hline N1 & 5 & $0.63(0.08-4.51)$ & 0.649 & & \\
\hline $\mathrm{N} 2$ & 7 & $1.39(0.23-8.32)$ & 0.721 & & \\
\hline N3a & 10 & $2.32(0.48-11.3)$ & 0.295 & & \\
\hline $\mathrm{N} 3 \mathrm{~b}$ & 17 & $1.11(0.23-5.35)$ & 0.897 & & \\
\hline \multicolumn{6}{|l|}{ Radical treatment } \\
\hline R0 & 30 & 1.00 & 1.000 & & \\
\hline $\mathrm{R} 1$ & 7 & $0.93(0.21-4.09)$ & 0.922 & & \\
\hline $\mathrm{R} 2$ & 8 & $2.24(0.67-7.54)$ & 0.194 & & \\
\hline \multicolumn{6}{|l|}{ Type of metastasis } \\
\hline Single site, non-peritoneal & 5 & 1.00 & 1.000 & & \\
\hline Peritoneal & 29 & $4.37(0.57-33.1)$ & 0.156 & & \\
\hline$>1$ type & 11 & $16.0(1.91-134.7)$ & 0.011 & $4.41(1.72-11.3)$ & 0.002 \\
\hline
\end{tabular}


Table 4 (continued)

*Analyzed as continuous variables

HIPEC hyperthermic intraperitoneal chemotherapy

Fig. 3 Kaplan-Meier curves of overall survival according to the type of extra-gastric involvement

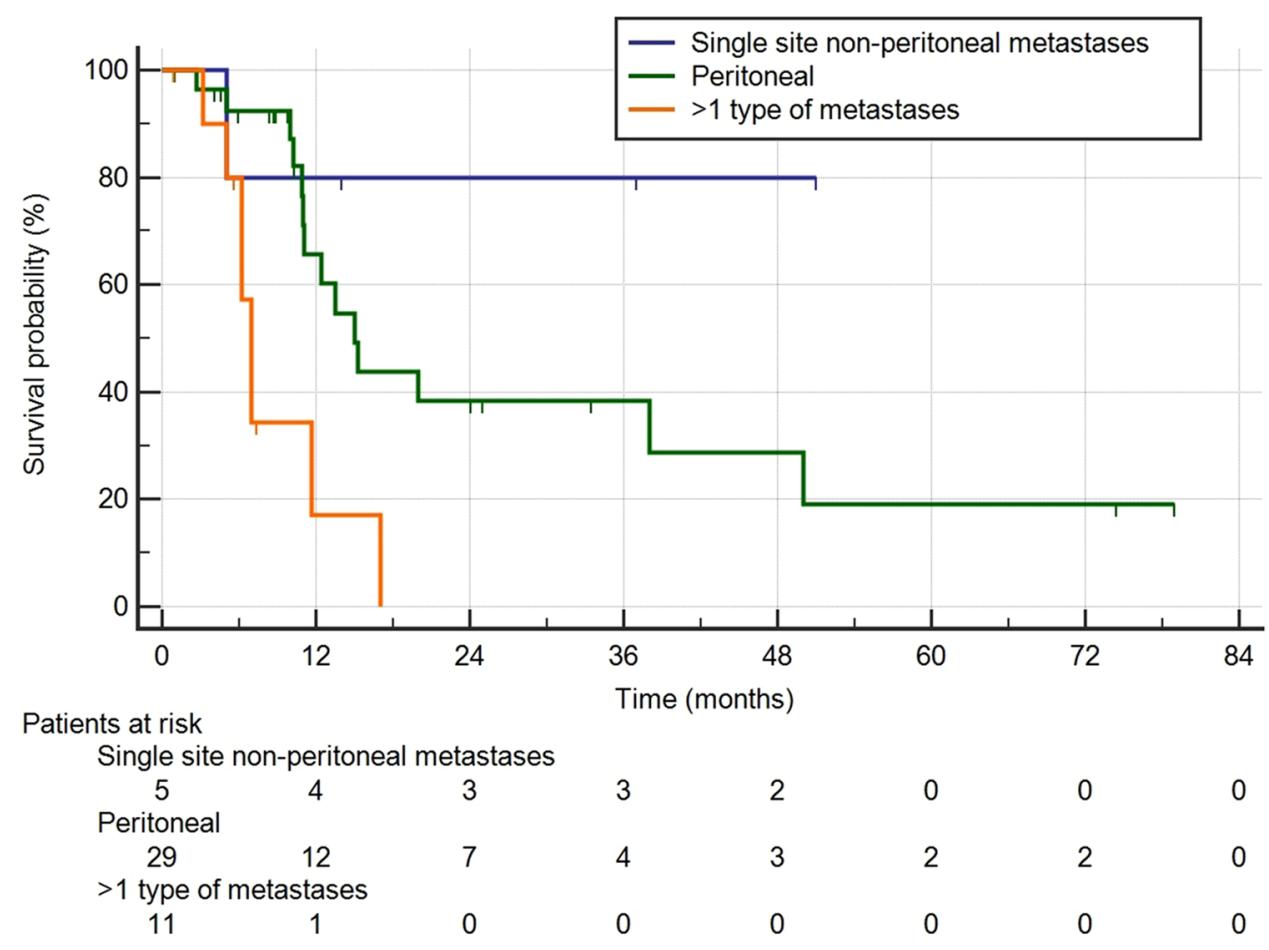

GC could become resectable after intensive chemotherapy and found that long survivors were only in the group of patients who could have radical surgery after chemotherapy.

Since then, an increasing number of researchers tried to investigate the role of the combination of preoperative/palliative/induction chemotherapy followed by surgery in the treatment of advanced unresectable gastric cancer. Currently, literature demonstrated that so-called conversion surgery for unresectable stage III or stage IV gastric cancer was associated with longer survival than chemotherapy alone. The most recent studies on stage III/IV unresectable patients undergoing conversion surgery reported survivals ranging from 37 to 56 months $[4,5,7,9-11,19-22]$.

The survival reported in our study is lower than those reported by others and this could be ascribed to the inclusion criteria we selected for our analysis. As such, our study population included only part of stage IV patients who had undergone chemotherapy plus surgery. In particular, we excluded from this study all stage IV GC patients who had chemotherapy plus surgery with $\mathrm{PCI} \leq 6$, unilobar technically resectable hepatic metastasis, only positive cytology or positive nodal metastases in D3 stations. As a consequence, our inclusion criteria identified a selected population composed mainly by Yoshida type 3 and 4 patients for whom an extraordinary response to chemotherapy could have led to the complete resection of the primary tumor and the peritoneal, nodal and liver metastases. As it has been highlighted by Yoshida et al. [16] and Yamaguchi et al. [11], peritoneal metastases in these cases may be technically resected but they often recur. In our study, a sub-population of Yoshida type 3 (macroscopic peritoneal dissemination without other organs involvement) patients showed unexpected survivals, being more than $35 \%$ alive 3 years after surgery. We believe that the results presented in this study may recommend not to exclude surgery a priori in selected advanced cases of stage IV GC.

In our analysis we found that more than one type of metastasis significantly affect prognosis. Similar findings were found by other authors [5, 10, 22], who showed that more than one non-curative factors were associated with a poor prognosis in unresectable GC patients. In light of those findings, it might be suggested not to proceed with surgery in those patients who have more than one district involved by metastases. Still, further data are required to confirm this hypothesis.

To date, the highest level of evidence about stage IV gastric cancer and the potential benefit of surgery in these patients is available thanks to the REGATTA trial [23]. This study showed that stage IV patients can benefit from surgery in terms of survival only when this is radical. Recently, these conclusions were also reached by the analyses of retrospective series of stage IV/unresectable patients undergoing 
Table 5 Cox regression analysis of disease-free survival

\begin{tabular}{|c|c|c|c|c|c|}
\hline \multirow[t]{3}{*}{ Variable } & \multirow[t]{3}{*}{$n$} & \multicolumn{4}{|l|}{$\mathrm{PFS}^{\circ}$} \\
\hline & & \multicolumn{2}{|l|}{ Univariate } & \multirow{2}{*}{$\begin{array}{l}\text { Multivariate } \\
\text { HR }(95 \% \text { CI) }\end{array}$} & \multirow[b]{2}{*}{$p$} \\
\hline & & $\mathrm{HR}(95 \% \mathrm{CI})$ & $P$ & & \\
\hline Age* & 34 & $0.99(0.95-1.04)$ & 0.744 & & \\
\hline \multicolumn{6}{|l|}{ Sex } \\
\hline Male & 21 & 1.00 & 1.000 & & \\
\hline Female & 13 & $0.93(0.38-2.29)$ & 0.871 & & \\
\hline \multicolumn{6}{|l|}{ ASA } \\
\hline$\leq 2$ & 33 & 1.00 & 1.000 & & \\
\hline$>2$ & 1 & $2.34(0.29-18.4)$ & 0.421 & & \\
\hline \multicolumn{6}{|l|}{$\mathrm{cT}$} \\
\hline cT3 & 7 & 1.00 & 1.000 & & \\
\hline cT4) & 25 & $2.33(0.51-10.6)$ & 0.275 & & \\
\hline $\mathrm{cN}(\mathrm{cN} 0 \mathrm{vs} \mathrm{cN}+)$ & & $0.65(0.31-1.36)$ & 0.258 & & \\
\hline \multicolumn{6}{|l|}{ Type of lymphadenectomy } \\
\hline D1 & 3 & $\S$ & 0.069 & & \\
\hline $\mathrm{D} 2$ & 13 & $2.37(0.93-6.02)$ & 1.000 & & \\
\hline D3 & 18 & 1.00 & & & \\
\hline \multicolumn{6}{|l|}{ Additional resection } \\
\hline No & 16 & 1.00 & 1.000 & & \\
\hline Yes & 18 & $0.53(0.20-1.34)$ & 0.187 & & \\
\hline \multicolumn{6}{|l|}{ HIPEC } \\
\hline No & 15 & 1.00 & 1.000 & & \\
\hline Yes & 19 & $0.69(0.26-1.84)$ & 0.469 & & \\
\hline \multicolumn{6}{|l|}{ Postoperative complications } \\
\hline No & 24 & 1.00 & 1.000 & & \\
\hline Yes & 10 & $2.53(0.16-1.20)$ & 0.112 & & \\
\hline Lymphnode harvested* & 45 & $1.01(0.97-1.06)$ & 0.466 & & \\
\hline \multicolumn{6}{|l|}{ Grading } \\
\hline $\mathrm{G} 2$ & 4 & 1.00 & 1.000 & & \\
\hline G3 & 24 & $2.99(0.39-22.7)$ & 0.292 & & \\
\hline \multicolumn{6}{|l|}{ Lauren's hystotype } \\
\hline Intestinal & 10 & 1.00 & 1.000 & & \\
\hline Diffuse & 19 & $2.00(0.63-6.39)$ & 0.244 & & \\
\hline Mixed & 4 & $4.38(0.95-20.2)$ & 0.059 & & \\
\hline \multicolumn{6}{|l|}{ pT } \\
\hline $\mathrm{pT}<4$ & 12 & 1.00 & 1.000 & & \\
\hline pT4a-b & 21 & $2.19(0.77-6.22)$ & 0.141 & & \\
\hline \multicolumn{6}{|l|}{$\mathrm{pN}$} \\
\hline No & 3 & $\S$ & 0.594 & & \\
\hline N1 & 2 & $\S$ & & & \\
\hline $\mathrm{N} 2$ & 5 & $0.66(0.14-3.00)$ & 0.438 & & \\
\hline $\mathrm{N} 3 \mathrm{a}$ & 8 & $1.49(0.54-4.12)$ & & & \\
\hline $\mathrm{N} 3 \mathrm{~b}$ & 14 & 1.00 & 1.000 & & \\
\hline \multicolumn{6}{|l|}{ Radical treatment } \\
\hline R0 & 30 & 1.00 & 1.000 & $5.72(1.04-31.4)$ & 0.045 \\
\hline $\mathrm{R} 1$ & 4 & $5.72(1.04-31.4)$ & 0.045 & & \\
\hline \multicolumn{6}{|l|}{ Type of metastasis } \\
\hline Single site, non-peritoneal & 5 & 1.00 & 1.000 & & \\
\hline Peritoneal & 21 & $0.90(0.19-4.16)$ & 0.895 & & \\
\hline$>1$ type & 8 & $3.29(0.64-16.8)$ & 0.153 & & \\
\hline
\end{tabular}

*Analyzed as continuous variables, $\S$ no cases of recurrence, calculated on 34 patients (of 37 R0-R1 patients, 3 did not have details about recurrence), HIPEC hyperthermic intraperitoneal chemotherapy 
induction chemotherapy followed by surgery $[5,11]$. Yamaguchi et al. [11] in their multi institutional study on 77 stage IV GC patients who had undergone conversion surgery found that median survival was 41.3 for R0 patients while it was 21.2 months for R1-2.

Our study, which is the largest in the western literature, confirmed that R0 conversion surgery was associated with a significantly longer PFS than R1 resections. In our opinion, this latter finding further highlights the importance of radical surgery in the attempt to improve survival in metastatic GC patients.

Current literature about conversion surgery lacks of standardized definitions as it was also highlighted by Terashima [12]: the criteria for initial determination of oncologically unresectable or determination of resectability postchemotherapy are heterogeneous among studies and results should always be interpreted in light of these differences. An effort from the scientific community would be required to find common definitions, and thus, reliable results in future studies.

The main limitation of this study is that the long study period covers several advances in oncology and, thus, in the chemotherapy regimens adopted. This resulted in a heterogeneous population in terms of type of chemotherapy used which made it difficult to understand the real impact of a regimen in the achievement of complete/partial response.

In conclusion, conversion gastrectomy is a treatment option for selected patients with stage IV GC. The main prognostic factor for these patients was the presence of more than one type of extra-gastric metastatic involvement. A radical procedure was significantly associated with a reduced risk of recurrence.

\section{Compliance with ethical standards}

Ethical standards All procedures followed were in accordance with the ethical standards of the responsible committee on human experimentation (institutional and national) and with the Helsinki Declaration of 1964 and later versions.

Conflict of interest The authors declare that they have no conflict of interest.

\section{References}

1. Japanese gastric cancer treatment guidelines 2014 (ver. 4). Gastric Cancer. 2017;20:1-19.

2. De Manzoni G, Marrelli D, Baiocchi GL, Morgagni P, Saragoni L, Degiuli M, et al. The Italian Research Group for Gastric Cancer (GIRCG) guidelines for gastric cancer staging and treatment: 2015. Gastric Cancer. 2017;20:20-30.

3. Shah MA. Update on metastatic gastric and esophageal cancers. J Clin Oncol. 2015;33:1760-9.
4. Einama T, Abe H, Shichi S, Matsui H, Kanazawa R, Shibuya K, et al. Long-term survival and prognosis associated with conversion surgery in patients with metastatic gastric cancer. Mol Clin Oncol. 2017;6:163-6.

5. Fukuchi M, Ishiguro T, Ogata K, Suzuki O, Kumagai Y, Ishibashi $\mathrm{K}$, et al. Prognostic role of conversion surgery for unresectable gastric cancer. Ann Surg Oncol. 2015;22:3618-24.

6. Kinoshita J, Fushida S, Tsukada T, Oyama K, Okamoto K, Makino I, et al. Efficacy of conversion gastrectomy following docetaxel, cisplatin, and S-1 therapy in potentially resectable stage IV gastric cancer. Eur J Surg Oncol. 2015;41:1354-60.

7. Morgagni P, Solaini L, Framarini M, Vittimberga G, Gardini A, Tringali D, et al. Conversion surgery for gastric cancer: a cohort study from a western center. Int J Surg. 2018;53:360-5.

8. Nakajima T, Ota K, Ishihara S, Oyama S, Nishi M, Ohashi Y, et al. Combined intensive chemotherapy and radical surgery for incurable gastric cancer. Ann Surg Oncol. 1997;4:203-8.

9. Saito M, Kiyozaki H, Takata O, Suzuki K, Rikiyama T. Treatment of stage IV gastric cancer with induction chemotherapy using S-1 and cisplatin followed by curative resection in selected patients. World J Surg Oncol. 2014;12:406.

10. Sato Y, Ohnuma H, Nobuoka T, Hirakawa M, Sagawa T, Fujikawa $\mathrm{K}$, et al. Conversion therapy for inoperable advanced gastric cancer patients by docetaxel, cisplatin, and S-1 (DCS) chemotherapy: a multi-institutional retrospective study. Gastric Cancer. 2017;20:517-26.

11. Yamaguchi K, Yoshida K, Tanahashi T, Takahashi T, Matsuhashi N, Tanaka Y, et al. The long-term survival of stage IV gastric cancer patients with conversion therapy. Gastric Cancer. 2017;21:315-23.

12. Terashima M. Conversion therapy for gastric cancer: who can make conversion as successful as Goromaru? Gastric Cancer. 2016;19:685-6.

13. Sugarbaker PH. A curative approach to peritoneal carcinomatosis from colorectal cancer. Semin Oncol. 2005;32:S68-73.

14. Lauren P. The two histological main types of gastric carcinoma: diffuse and so-called intestinal-type carcinoma: an attempt at a histo-clinical classification. Acta Pathol Microbiol Scand. 1965;64:31-49.

15. Edge S, Byrd D, Compton C. AJCC Cancer Staging Manual, edn 7. New York: Springer; 2010.

16. Yoshida K, Yamaguchi K, Okumura N, Tanahashi T, Kodera Y. Is conversion therapy possible in stage IV gastric cancer: the proposal of new biological categories of classification. Gastric Cancer. 2016;19:329-38.

17. Dindo D, Demartines N, Clavien PA. Classification of surgical complications: a new proposal with evaluation in a cohort of 6336 patients and results of a survey. Ann Surg. 2004;240:205-13.

18. Schemper M, Smith TL. A note on quantifying follow-up in studies of failure time. Control Clin Trials. 1996;17:343-6.

19. Kanda T, Yajima K, Kosugi S, Ishikawa T, Ajioka Y, Hatakeyama $\mathrm{K}$. Gastrectomy as a secondary surgery for stage IV gastric cancer patients who underwent S-1-based chemotherapy: a multi-institute retrospective study. Gastric Cancer. 2012;15:235-44.

20. Mieno H, Yamashita K, Hosoda K, Moriya H, Higuchi K, Azuma $\mathrm{M}$, et al. Conversion surgery after combination chemotherapy of docetaxel, cisplatin and S-1 (DCS) for far-advanced gastric cancer. Surg Today. 2017;47:1249-58.

21. Okabe H, Ueda S, Obama K, Hosogi H, Sakai Y. Induction chemotherapy with S-1 plus cisplatin followed by surgery for treatment of gastric cancer with peritoneal dissemination. Ann Surg Oncol. 2009; 16:3227-36.

22. Uemura N, Kikuchi S, Sato Y, Ohnuma H, Okamoto K, Miyamoto $\mathrm{H}$, et al. A phase II study of modified docetaxel, cisplatin, and S-1 (mDCS) chemotherapy for unresectable advanced gastric cancer. Cancer Chemother Pharmacol. 2017;80:707-13. 
23. Fujitani K, Yang HK, Mizusawa J, Kim YW, Terashima M, Han SU, et al. Gastrectomy plus chemotherapy versus chemotherapy alone for advanced gastric cancer with a single non-curable factor (REGATTA): a phase 3, randomised controlled trial. Lancet Oncol. 2016;17:309-18.
Publisher's Note Springer Nature remains neutral with regard to jurisdictional claims in published maps and institutional affiliations. 